\title{
BMJ Open Maternal education, empowerment, economic status and child polio vaccination uptake in Pakistan: a population based cross sectional study
}

\author{
Muhammad Tahir Khan, ${ }^{1}$ Sidra Zaheer, ${ }^{1}$ Kashif Shafique ${ }^{1,2}$
}

To cite: Khan MT, Zaheer S, Shafique K. Maternal education, empowerment, economic status and child polio vaccination uptake in Pakistan: a population based cross sectional study. BMJ Open 2017;7:e013853. doi:10.1136/bmjopen-2016013853

- Prepublication history for this paper is available online. To view these files please visit the journal online (http://dx.doi.org/10.1136/ bmjopen-2016-013853).

MTK and SZ contributed equally to the work

Received 15 August 2016 Revised 8 February 2017 Accepted 10 February 2017

CrossMark

\footnotetext{
${ }^{1}$ School of Public Health, Dow University of Health Sciences, Karachi, Pakistan ${ }^{2}$ Institute of Health and Wellbeing, Public Health, University of Glasgow, Glasgow, UK
}

Correspondence to Dr Muhammad Tahir Khan; tahir.khan@duhs.edu.pk

\section{ABSTRACT}

Objectives: To explore the association of maternal education and empowerment with childhood polio vaccination using nationally representative data of Pakistani mothers in a reproductive age group.

Design: Cross-sectional.

Setting: Secondary analysis of Pakistan Demographic and Health Survey (PDHS), 2012-2013 data was performed.

Participants: Of the 13558 mothers included in the survey sample, 6982 mothers were able to provide information regarding polio vaccinations.

Main outcome measures: Polio vaccination coverage among children aged up to 5 years was categorised as complete vaccination (all four oral polio vaccine (OPV) doses), incomplete vaccination, and no vaccination (zero OPV dose received). Mothers' empowerment status was assessed using standard 'Measure DHS' questions regarding their involvement in decision-making related to health, household possessions and visits among family and friends. Education was categorised as no education, primary, secondary and higher education. Results of multinomial regression analyses were reported as adjusted OR with $95 \% \mathrm{Cl}$. We adjusted for age, wealth index, urban/rural residence, place of delivery, and antenatal and postnatal visits.

Results: Only $56.4 \%$ ( $n=3936)$ of the children received complete polio vaccination. Women with no education had significantly higher odds of their child receiving no polio vaccination (OR $2.34,95 \% \mathrm{Cl} 1.05$ to $5.18 ; p<0.01)$ and incomplete vaccination (OR 1.40, $95 \% \mathrm{Cl} 1.04$ to $1.87 ; p<0.01)$. Further, unempowered women also had significantly higher odds of not taking their child for any polio vaccination (OR $1.58,95 \% \mathrm{Cl}$ 1.17 to $2.12 ; \mathrm{p}<0.01)$ and incomplete vaccination $(\mathrm{OR}$ $1.18,95 \% \mathrm{Cl} 1.00$ to $1.41 ; \mathrm{p}=0.04$ ).

Conclusions: Illiteracy, socioeconomic status and empowerment of women remained significant factors linked to poorer uptake of routine polio vaccination.

\section{INTRODUCTION}

After the re-emergence of polio cases in Nigeria in 2016, the number of countries where polio is endemic is again three.

\section{Strengths and limitations of this study}

- This study for the first time discusses the maternal factors associated with polio vaccination uptake in Pakistan using nationally representative population based data.

- The reason for low vaccination uptake could not be established. Whether poor vaccination status was due to parental refusal or simply because of lack of access to healthcare facilities cannot be established with certainty.

- The possible qualitative heterogeneity in the sample is not possible to control entirely.

- The Pakistan Demographic and Health Survey (PDHS) 2012-2013 data did not include information on religious beliefs as possible barriers to vaccination uptake, a major debate in the context of Pakistan.

- Despite the use of vaccination cards in reporting of the polio vaccination status, data also relied on self-report from mothers. This could have caused potential recall bias.

Pakistan, with over 350 cases of wild polio virus (WPV) in the past 2 years (2014 and 2015, compared to just 47 cases in Afghanistan during the same period), is becoming the last refuge for this crippling disease. ${ }^{12}$ With a high population burden, a poor law and order situation and an overwhelming influx of potentially unvaccinated refugees from the north west, the Pakistani government and international agencies need to understand the factors which must be tackled in order to eradicate polio from this region. ${ }^{3}$

Despite all efforts, optimal vaccination remains the cornerstone in disrupting WPV transmission in the country. According to the Pakistan Demographic Health Survey (PDHS) 2012-2013, 85\% of children in the country are reported to be vaccinated (with three doses of oral polio vaccine (OPV)) against polio. Although the trend shows a 
substantial increase in polio vaccination uptake between 1990-1991 and 2006-2007, a plateau in vaccination uptake has now been observed in the 2012-2013 survey. ${ }^{4}$ However, possible disparities might still exist between the urban and rural populations and between different sociodemographic factions.

Of all the factors associated with satisfactory vaccination uptake, the role of the mother is of key importance. It has been reported that maternal education, empowerment and economic conditions are major determinants in achieving better vaccination uptake in both developed and lower/middle income countries. ${ }^{5-9}$ In Pakistan, there is hardly any robust evidence regarding maternal characteristics and their relationship with routine vaccination uptake. Until a better understanding is established, mass vaccination campaigns and the national Expanded Program for Immunization (EPI) will continue to deliver suboptimal vaccination in Pakistan resulting in continued outbreaks.

In the present study we examined the maternal characteristics and their association with polio vaccination uptake using the nationally representative population-based data of women in the reproductive age group.

\section{METHODS}

\section{Data source}

Data from the third national population based demographic and health survey (PDHS 2012-2013) was used in this study. This survey was designed to gather information from ever-married Pakistani women of reproductive age. PDHS 2012-2013 data included information on demographic characteristics, mother and child health and nutrition, HIV/AIDS related issues, women empowerment and domestic violence. ${ }^{4}$

\section{Sampling method and sample size}

The multistage cluster sampling method was employed to collect data. The sampling design was developed by the National Institute of Population Studies (NIPS) and the Pakistan Bureau of Statistics. Sampling areas were initially selected and from them 248 urban and 252 rural units were selected. Households were selected through systematic sampling for each area, finally selecting households from 944 urban areas and 7056 rural areas. ${ }^{4}$

\section{Survey participants}

A total of 14569 ever married women aged between 15 and 49 years were eligible and 13558 completed the interview, making a response rate of $93.1 \%$. However, since we included only mothers who had children up to 5 years of age, data from a total of 6982 mothers were used.

\section{Study design and sample}

Secondary analysis of the nationally representative PDHS 2012-2013 was performed. Data on polio vaccination uptake among children up to 5 years of age was used for this study.

\section{Data collection tool}

The questionnaire used for the PDHS 2012-2013 was developed using the MEASURE DHS Program which was structured, pretested and modified to suit Pakistani context. $^{4}$

\section{Ethical considerations}

PDHS complies with standard ethical guidelines of the MEASURE DHS Program, and data for the current study were obtained from the MEASURE DHS website following their standard data obtaining procedure. ${ }^{4}$

\section{Study variables}

Dependent variable: In the 2012-2013 PDHS, information on polio vaccination uptake was collected in two ways: either from vaccination cards or verbal reports. If the vaccination card was shown, the interviewer copied the vaccination dates directly. If no vaccination card was available, the respondent was asked to recall specific vaccines administered to the child using the following question about each child:

1. Has (NAME) had any vaccinations that are not recorded on this card, including vaccinations given in a national immunization day campaign? Response options were yes, no and don't know.

2. Did (NAME) ever have any vaccinations to prevent him/her from getting diseases, including vaccinations received in a national immunization day campaign? Response options were yes, no and don't know.

3. Please tell me if (NAME) had any of the following vaccinations:

4. Polio vaccine, that is, drops in the mouth? Response options were yes, no and don't know.

5. How many times was the polio vaccine given? Response option was number of times.

By using all the above collected information (vaccination card or mother's report), polio vaccination uptake among children aged up to 5 years was categorised as complete vaccination (all four OPV doses received), incomplete vaccination, and no vaccination (zero OPV dose received).

Independent variables: Mothers' empowerment status was assessed using standard 'Measure DHS' questions regarding their involvement in decision-making related to own health, household possessions and visits among family and friends. Questions include:

1. Who usually makes decisions about healthcare for yourself: you, your husband, you and your husband jointly, or someone else?

2. Who usually makes decisions about making major household purchases: you, your husband, you and your husband jointly, or someone else? 
3. Who usually makes decisions about visits to your family or relatives: you, your husband, you and your husband jointly, or someone else?

Mothers who were directly involved in decision-making for any of the above indicators were labelled as 'Empowered'; other responses were labelled as 'Unempowered'. Education was assessed by asking questions "Have you ever attended school?" and "What is the highest class you completed?". Education was categorised as (1) no education, (2) primary, (3) secondary and (4) higher education. Similarly, wealth index was determined using housing characteristics and assets and was reported as a wealth index using categories (1) poorest, (2) poorer, (3) middle, (4) richer and (5) richest. $^{10}$

\section{Statistical analyses}

SAS V.9.1.3 was used for data analysis. Complex survey data analysis was employed, as the PDHS 2012-2013 followed multistage cluster sampling design. Primary sampling units, final weights and strata were used to adjust for cluster sampling. The $\chi^{2}$ test was used to determine the significance of association between variables. Weighted multinomial regression analyses were used; results were reported as crude and adjusted (adjusting for mother's age, mother's education level, wealth index, and urban/rural type of residence, place of delivery, antenatal and postnatal visits) OR with 95\% CIs. A value of $\mathrm{p}<0.05$ was considered significant.

\section{RESULTS}

Of the 13558 mothers included in the survey sample, 6982 were able to provide information regarding polio vaccinations. Results found that only $56.4 \%$ ( $\mathrm{n}=3936)$ of the children received complete polio vaccination, 33.3\% $(\mathrm{n}=2329)$ received incomplete vaccination, and $10.3 \%$ $(n=717)$ of the children did not receive any OPV doses.

Table 1 shows that the children of mothers aged 1524 years were more likely to be unvaccinated $\left(\chi^{2}=21.8\right.$, $\mathrm{p}<0.01)$ than children of mothers aged $\geq 25$ years. Complete polio vaccination uptake rate was higher in urban areas compared to rural areas $(62.6 \%$ vs $51.4 \%$, $\left.\chi^{2}=100.8, \mathrm{p}<0.01\right)$. There was a positive relationship between the mothers' level of education and the polio vaccination uptake for their children $\left(\chi^{2}=391.7, \mathrm{p}<0.01\right)$, where $74.4 \%$ of children of mothers with higher education were completely vaccinated compared to $66.9 \%$ of those with secondary education and $62.3 \%$ and $47.1 \%$ of those with primary and with no education, respectively. We also observed the highest percentage of completely vaccinated children $(72.6 \%)$ among mothers of the richest quintile followed by $63.4 \%, 58.0 \%, 49.8 \%$ and $39 \%$ for the richer, middle, poorer and poorest wealth quintiles, respectively $\left(\chi^{2}=442.2, \mathrm{p}<0.01\right)$. Furthermore, children of unempowered mothers were significantly less likely to be completely vaccinated $\left(\chi^{2}=90.9, p<0.01\right)$.
Results of the multinomial regression are presented in table 2; we found the effects of independent variables on the child polio vaccination uptake, using 'complete vaccination' as the reference category. Univariate multinomial regression (Model 0) indicates that incomplete polio vaccination was associated with living in a rural setting (OR 1.68, 95\% CI 1.41 to 2.01), no education (OR 2.70, 95\% CI 2.03 to 3.58), belonging to the poorest wealth quintile (OR 3.31, 95\% CI 2.48 to 4.41 ) and unempowerment (OR 1.36, 95\% CI 1.14 to 1.62 ). Children of mothers aged $\geq 35$ years were less likely to be incompletely vaccinated (OR $0.75,95 \%$ CI 0.62 to $0.91)$. No polio vaccination was associated with unempowerment (OR 2.16, 95\% CI 1.61 to 2.91), residence in rural setting (OR $3.00,95 \%$ CI 1.98 to 4.54 ), no education (OR 10.37, 95\% CI 4.72 to 22.76) and poorest wealth quintile (OR 9.65, 95\% CI 5.31 to 17.53). Children of mothers aged 25-34 years were less likely to be unvaccinated (OR $0.63,95 \%$ CI 0.48 to 0.83 ).

Multivariate results (Model 1) showed that the mother's education and socioeconomic status remained the significant factors for having a child completely vaccinated against polio after adjusting for other variables. Children of mothers with no education had significantly higher odds of no vaccination (OR 2.34, 95\% CI 1.05 to 5.18 ) and incomplete vaccination (OR $1.40,95 \%$ CI 1.04 to 1.87). Similarly children of unempowered mothers also had significantly higher odds of no vaccination (OR 1.58, 95\% CI 1.17 to 2.12) and incomplete vaccination (OR 1.18, 95\% CI 1.00 to 1.41) (table 2).

To assess the relationship of maternal factors with polio vaccination uptake in relation to their area of residence (whether urban or rural), we stratified our analysis based on place of residence. The association of education level and wealth quintile with no polio vaccination is depicted in figures 1 and 2. Results showed that children of mothers who were uneducated were more likely to be unvaccinated (urban: AOR 4.42, 95\% CI 1.49 to 13.12; rural: AOR 3.95, 95\% CI 1.11 to 13.92). Similarly, children of mothers who belonged to the poorest wealth quintile were also more likely to be unvaccinated (urban: AOR 2.28, 95\% CI 0.78 to 6.66; rural: AOR 2.42, $95 \%$ CI 0.96 to 6.08 ).

\section{DISCUSSION}

This study showed that $<60 \%$ of the children were completely vaccinated and over $10 \%$ of the children did not receive any polio vaccination at all. Apart from the security related issues which have badly threatened the mass polio vaccination campaigns in the country, ${ }^{3}$ there are many factors affecting the uptake of the vaccination. One of the most important is the role played by mothers in getting their children vaccinated. We found that maternal unempowerment, younger age, lower educational level and income were strongly linked with no vaccination of their children. Similarly, partial or incomplete polio vaccination was found to be most 
Table 1 Descriptive characteristics of women regarding polio vaccination uptake $(n=6982)$

\begin{tabular}{|c|c|c|c|c|}
\hline & $\begin{array}{l}\text { Complete vaccination } \\
\text { (all four OPV doses) }\end{array}$ & $\begin{array}{l}\text { Incomplete } \\
\text { vaccination }\end{array}$ & $\begin{array}{l}\text { No vaccination } \\
\text { (zero OPV doses) }\end{array}$ & p Value* \\
\hline \multicolumn{5}{|c|}{ Mother's age (years) } \\
\hline $15-24$ & 833 (51.7) & 593 (36.8) & $184(11.4)$ & \multirow[t]{3}{*}{$<0.01$} \\
\hline $25-34$ & $2172(58.2)$ & 1207 (32.4) & $351(9.4)$ & \\
\hline$\geq 35$ & $931(56.7)$ & 529 (32.2) & $182(11.1)$ & \\
\hline \multicolumn{5}{|l|}{ Place of residence } \\
\hline Urban & 1939 (62.6) & 927 (29.9) & $231(7.5)$ & \multirow[t]{2}{*}{$<0.01$} \\
\hline Rural & 1997 (51.4) & $1402(36.1)$ & $486(12.5)$ & \\
\hline \multicolumn{5}{|c|}{ Mother's education level } \\
\hline Higher & $649(74.4)$ & 207 (23.7) & $16(1.8)$ & \multirow[t]{4}{*}{$<0.01$} \\
\hline Secondary & $864(66.9)$ & $370(28.7)$ & $57(4.4)$ & \\
\hline Primary & $623(62.3)$ & 303 (30.3) & $74(7.4)$ & \\
\hline No education & $1800(47.1)$ & 1449 (37.9) & $570(14.9)$ & \\
\hline \multicolumn{5}{|l|}{ Wealth index } \\
\hline Richest & 1037 (72.6) & $329(23.0)$ & $62(4.3)$ & \multirow[t]{5}{*}{$<0.01$} \\
\hline Richer & 860 (63.4) & 404 (29.8) & $92(6.8)$ & \\
\hline Middle & $771(58.0)$ & 447 (33.6) & $112(8.4)$ & \\
\hline Poorer & $687(49.8)$ & $519(37.6)$ & $173(12.5)$ & \\
\hline Poorest & $581(39.0)$ & $630(42.3)$ & $278(18.7)$ & \\
\hline \multicolumn{5}{|c|}{ Mother's empowerment status } \\
\hline Empowered & $2241(60.6)$ & $1182(32.0)$ & $275(7.4)$ & \multirow[t]{2}{*}{$<0.01$} \\
\hline Unempowered & $1695(51.6)$ & $1147(34.9)$ & $442(13.5)$ & \\
\hline
\end{tabular}

strongly associated with poverty, illiteracy (no education) and younger age of the mother. Mother's lack of empowerment remained weak yet significantly associated with incomplete vaccination. However, place of residence (urban or rural) was not found to have an effect on 'Incomplete' or 'No' vaccination after adjusting for mother's age, empowerment status, education and wealth index. This finding indicates a possible effect of internal migration and increased urbanisation, decreasing the positive effects of living in an urban environment on vaccination uptake. The role of the mother in her child's health is well established. Whether it may be the child's nutritional status or psychological development, physical well-being or healthcare decisions, an empowered, educated mother plays a definitive role. Mother's education is repeatedly reported to be a key determinant in children's health and vaccination status in many studies from various settings. ${ }^{5-8}$ We found a classic trend when looking at the effect of maternal education on the vaccination status of children, with the chances of incomplete or no vaccination increasing alongside decreasing maternal education. Our study found that maternal illiteracy increased the odds of incomplete or no vaccination against polio among children by 1.5 and 4 times, respectively, compared to the mothers with higher education. Similarly, a mother's primary education (when compared with higher education) was also found to be a strong factor for 'no vaccination', increasing the odds by almost threefold. Although some studies report that even a little maternal education is positively associated with better child health, in our case, probably the complex dynamics of rumours and the defamation of the vaccination campaigns are responsible for undermining the effect of primary education. The reason we considered only the mother's and not the father's education is to avoid the co-linearity effect. Both these variables were found to be strongly correlated, hence the father's education was not included in the multivariate analyses.

The role of women empowerment in child health is generally reported to have a positive effect. However, the term itself is defined varyingly in the literature, with parameters such as conjugal power, autonomy, empowerment, maternal agency and decision-making. ${ }^{11}$ Studies considering national level data from middle and low income countries show a general trend of positive association between mother's empowerment and child vaccination with occasional inconsistent findings. ${ }^{12-21}$ We found a positive association between maternal empowerment and complete polio vaccination of their children. The parameters taken to assess the empowerment of mothers were mainly their involvement in decisionmaking regarding family, healthcare and other issues.

Socioeconomic status, reported in our study as wealth quintiles, has the strongest association with complete vaccination against polio. Compared to the richest category, the risk of incomplete vaccination increased consistently and significantly among lower categories. However, the risk of no vaccination was significantly higher in the bottom two categories only (odds of two and four times in poorer and poorest, respectively). The classical trend of increasing risk of incomplete 


\begin{tabular}{|c|c|c|c|c|c|c|c|c|}
\hline \multirow{4}{*}{$\begin{array}{l}\text { Characteristics } \\
\text { Complete vaccination (ref) }\end{array}$} & \multicolumn{4}{|l|}{ Model 0} & \multicolumn{4}{|l|}{ Model 1} \\
\hline & OR (95\% Cl) & $p$ Value & OR (95\% Cl) & p Value & OR (95\% Cl) & $p$ Value & OR (95\% Cl) & p Value \\
\hline & \multicolumn{8}{|c|}{ Polio vaccination uptake } \\
\hline & \multicolumn{2}{|c|}{ Incomplete vaccination } & No vaccination & & \multicolumn{2}{|c|}{ Incomplete vaccination } & \multicolumn{2}{|l|}{ No vaccination } \\
\hline \multicolumn{9}{|l|}{ Mother's empowerment status } \\
\hline Empowered & 1 & & 1 & & 1 & & 1 & \\
\hline Unempowered & 1.36 (1.14 to 1.62$)$ & $<0.01$ & 2.16 (1.61 to 2.91$)$ & $<0.01$ & $1.18(1.00$ to 1.41$)$ & 0.04 & 1.58 (1.17 to 2.12$)$ & $<0.01$ \\
\hline \multicolumn{9}{|l|}{ Mother's age (years) } \\
\hline $15-24$ & 1 & & 1 & & 1 & & 1 & \\
\hline $25-34$ & 0.74 (0.63 to 0.87$)$ & $<0.01$ & 0.63 (0.48 to 0.83$)$ & $<0.01$ & 0.78 (0.66 to 0.92$)$ & $<0.01$ & 0.67 (0.48 to 0.92$)$ & 0.01 \\
\hline$\geq 35$ & 0.75 (0.62 to 0.91$)$ & $<0.01$ & 0.78 (0.59 to 1.04$)$ & 0.10 & $0.70(0.57$ to 0.86$)$ & $<0.01$ & 0.66 (0.47 to 0.94$)$ & 0.02 \\
\hline \multicolumn{9}{|l|}{ Place of residence } \\
\hline Urban & 1 & & 1 & & 1 & & 1 & \\
\hline Rural & $1.68(1.41$ to 2.01$)$ & $<0.01$ & $3.00(1.98$ to 4.54$)$ & $<0.01$ & $0.97(0.79$ to 1.20$)$ & 0.83 & $1.16(0.75$ to 1.79$)$ & 0.48 \\
\hline \multicolumn{9}{|l|}{ Mother's education level } \\
\hline Higher & 1 & & 1 & & 1 & & 1 & \\
\hline Secondary & 1.34 (1.02 to 1.77$)$ & 0.03 & $2.39(1.08$ to 5.28$)$ & 0.03 & $1.07(0.81$ to 1.40$)$ & 0.41 & $1.58(0.70$ to 3.55$)$ & 0.13 \\
\hline Primary & $1.76(1.30$ to 2.37$)$ & $<0.01$ & 4.79 (2.18 to 10.53$)$ & $<0.01$ & $1.13(0.82$ to 1.55$)$ & 0.18 & 2.07 (0.91 to 4.71$)$ & $<0.01$ \\
\hline No education & 2.70 (2.03 to 3.58$)$ & $<0.01$ & 10.37 (4.72 to 22.76$)$ & $<0.01$ & $1.40(1.04$ to 1.87$)$ & $<0.01$ & 2.34 (1.05 to 5.18$)$ & $<0.01$ \\
\hline \multicolumn{9}{|l|}{ Wealth index } \\
\hline Richest & 1 & & 1 & & 1 & & 1 & \\
\hline Richer & $1.51(1.18$ to 1.90$)$ & $<0.01$ & 2.04 (1.25 to 3.33$)$ & $<0.01$ & $1.26(0.98$ to 1.61$)$ & 0.06 & $1.05(0.58$ to 1.87$)$ & 0.87 \\
\hline Middle & 2.11 (1.62 to 2.77$)$ & $<0.01$ & 2.05 (1.25 to 3.35$)$ & $<0.01$ & 1.57 (1.19 to 2.07$)$ & $<0.01$ & $0.72(0.40$ to 1.30$)$ & 0.28 \\
\hline Poorer & 2.48 (1.91 to 3.24$)$ & $<0.01$ & 4.84 (2.88 to 8.12$)$ & $<0.01$ & $1.70(1.23$ to 2.35$)$ & $<0.01$ & $1.29(0.68$ to 2.45$)$ & 0.43 \\
\hline Poorest & 3.31 (2.48 to 4.41$)$ & $<0.01$ & 9.65 (5.31 to 17.53$)$ & $<0.01$ & 2.11 (1.51 to 2.94$)$ & $<0.01$ & $2.10(1.02$ to 4.31$)$ & 0.04 \\
\hline \multicolumn{9}{|c|}{$\begin{array}{l}\text { Model 0: univariate multinomial regression analysis. } \\
\text { Model 1: adjusted multinomial logistic regression for mother's empowerment status, age, place of residence, mother's education, wealth index, place of delivery, antenatal visits, postnatal visits. }\end{array}$} \\
\hline
\end{tabular}

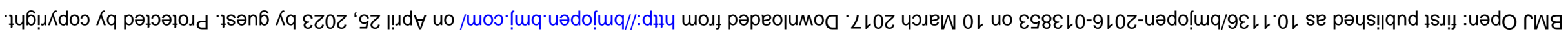




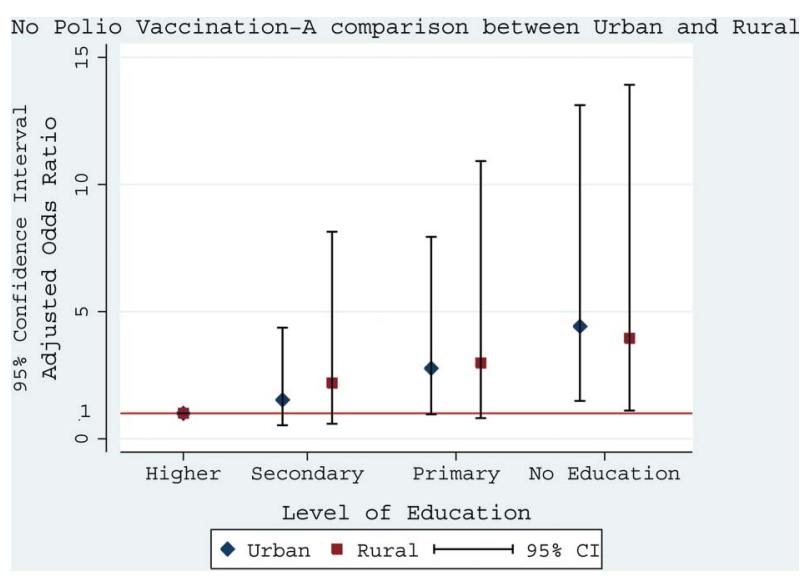

Figure 1 Comparison of no polio vaccination uptake and education between urban and rural place of residence.

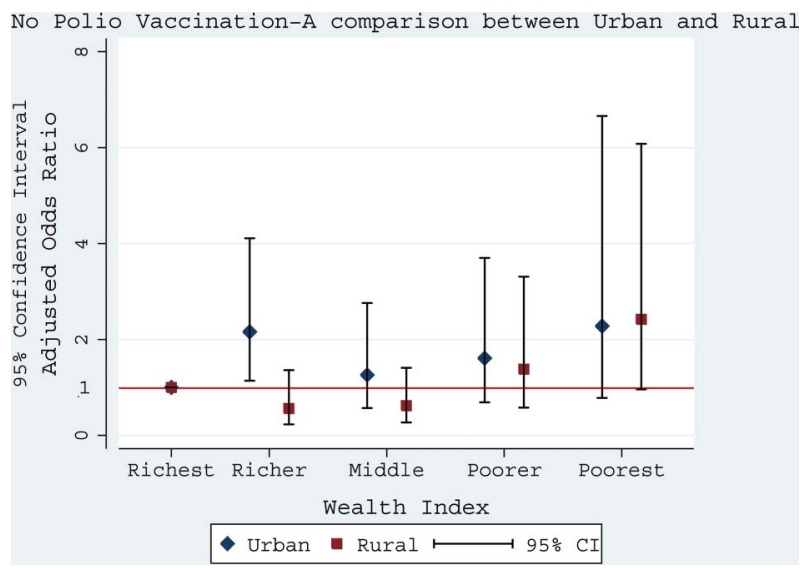

Figure 2 Comparison of no polio vaccination uptake and wealth index between urban and rural place of residence.

vaccination with decreasing wealth index calls for particular measures especially in terms of mass vaccination campaigns to help reduce the gap between complete and incomplete vaccination status, as the burden of children with incomplete polio vaccination is three times that of children with no vaccination.

Maternal age $<20$ years is reported to be a barrier to both completeness and timeliness of vaccination among children in both developed and lower/middle income countries. ${ }^{7} 22{ }^{23}$ In our study, maternal age $<25$ years was found to be most strongly associated with incomplete vaccination, with $20-30 \%$ protective effect against incomplete vaccination if the mother was over 25 years old. This could probably be due to better understanding of the child's health with increasing maternal age. In addition, mothers aged 35 years and above are likely to have more than one child considered in the analysis, so understanding of health related issues increases accordingly.

Although the literature reports the risk of incomplete vaccination in rural settings, ${ }^{23-26}$ we did not find any such difference after adjusting for mother's age, empowerment status, education and wealth index. This finding is important in a sense that maternal factors posing risks to poor polio vaccination uptake are similar across urban and rural Pakistan and can be dealt by making uniform policies. Similarly, the effect of poverty and low education on 'no vaccination' was consistent in both urban and rural settings.

Some researchers have reported that religious beliefs are one of the most difficult obstacles to vaccination in general and OPV specifically. ${ }^{27}{ }^{28}$ Although some authors support the proposal that maternal religious affiliation with Islam increases the chances of no vaccination, ${ }^{24}$ this barrier can be lifted significantly if the proper enabling factors are identified and community gatekeepers are also involved. Pakistan is a country where the majority of the population attach high values to religious norms. The participation of religious leaders has shown positive impacts in the past. ${ }^{29}$

After the mistrust that was created in the general population after the hepatitis $B$ vaccination related event in $2011,{ }^{30}$ and the decades old rumours that polio vaccination campaigns are western plots to sterilise girls, the situation has become much worse. The effect has been very clearly shown by the killing of polio workers, the increased number of polio cases reported between 2014 and 2016, and the attitudes of parents towards polio vaccination as reflected in the Harvard polls. ${ }^{31}{ }^{32}$ There is no doubt that the global war against polio is ultimately being fought on the frontiers of Pakistan. This war cannot be won until it is augmented by the mothers. Consequently, an educated, empowered mother can help overcome the barriers faced in eliminating this crippling disease.

\section{CONCLUSIONS}

Maternal factors such as education, empowerment and age, as well as socioeconomic status, were found to be most strongly associated with complete vaccination against polio in a Pakistani population.

Acknowledgements Authors acknowledge the work of the team that conducted the Pakistan Demographic and Health Survey 2012-2013.

Contributors MTK and SZ conceived the idea for the study, ran the statistical analysis, wrote the first draft and have contributed equally. KS contributed throughout the drafting of the manuscript.

Funding This research received no specific grant from any funding agency in the public, commercial or not-for-profit sectors.

Competing interests None declared.

Ethics approval DHS Measures.

Provenance and peer review Not commissioned; externally peer reviewed.

Data sharing statement No additional data are available.

Open Access This is an Open Access article distributed in accordance with the Creative Commons Attribution Non Commercial (CC BY-NC 4.0) license, which permits others to distribute, remix, adapt, build upon this work noncommercially, and license their derivative works on different terms, provided the original work is properly cited and the use is non-commercial. See: http:// creativecommons.org/licenses/by-nc/4.0/ 


\section{REFERENCES}

1. ReliefWeb. Polio this week as of 13 January 2016. Secondary Polio this week as of 13 January 201613 Jan 2016 2016. http://reliefweb. int/report/world/polio-week-13-january-2016

2. Centers for Disease Control and Prevention. Updates on CDC's Polio Eradication Efforts. Secondary Updates on CDC's Polio Eradication Efforts January 27, 2016 2016. http://www.cdc.gov/polio/ updates/2016/2016-0129.htm

3. Ahmad SO, Yousuf F, Bux AS, et al. Pakistan: the final frontier for global polio eradication. J Epidemiol Community Health 2016;70:109-10.

4. NIPS II. Pakistan Demographic and Health Survey 2012-13. Secondary Pakistan Demographic and Health Survey 2012-13. 2013. http://www.nips.org.pk/abstract_files/Priliminary\%20Report\% 20Final.pdf

5. Jani JV, Schacht C, Jani IV, et al. Risk factors for incomplete vaccination and missed opportunity for immunization in rural Mozambique. BMC Public Health 2008;8:1.

6. Bondy JN, Thind A, Koval JJ, et al. Identifying the determinants of childhood immunization in the Philippines. Vaccine 2009;27:169-75.

7. Kusuma YS, Kumari R, Pandav CS, et al. Migration and immunization: determinants of childhood immunization uptake among socioeconomically disadvantaged migrants in Delhi, India. Trop Med Int Health 2010;15:1326-32.

8. Calhoun LM, van Eijk AM, Lindblade KA, et al. Determinants and coverage of vaccination in children in western Kenya from a 2003 cross-sectional survey. Am J Trop Med Hyg 2014;90:234-41.

9. Thorpe S, VanderEnde K, Peters $\mathrm{C}$, et al. The influence of women's empowerment on child immunization coverage in low, lower-middle, and upper-middle income countries: a systematic review of the literature. Matern Child Health J 2016;20:172-86.

10. Measure D, Calverton M. Demographic and health survey. ORC Macro, 1994.

11. Kabeer N. Resources, agency, achievements: reflections on the measurement of women's empowerment. Development Change 1999:30:435-64.

12. Babalola S. Determinants of the uptake of the full dose of Diphtheria-Pertussis-Tetanus vaccines (DPT3) in northern Nigeria: a multilevel analysis. Matern Child Health J 2009;13:550-8.

13. Mahapatro S. Utilization of maternal and child health care services in India: does women's autonomy matter? J Fam Welfare 2012;58:22-33.

14. Vikram K, Vanneman R, Desai S. Linkages between maternal education and childhood immunization in India. Soc Sci Med 2012;75:331-9.

15. Rahman M, Obaida-Nasrin S. Factors affecting acceptance of complete immunization coverage of children under five years in rural Bangladesh. Salud pública de méxico 2010;52:134-40.
16. Parashar S. Moving beyond the mother-child dyad: women's education, child immunization, and the importance of context in rural India. Soc Sci Med 2005;61:989-1000.

17. Agarwal S, Srivastava A. Social determinants of children's health in urban areas in India. $J$ Health Care Poor Underserved 2009;20 (4A):68-89.

18. Abuya BA, Onsomu EO, Kimani JK, et al. Influence of maternal education on child immunization and stunting in Kenya. Matern Child Health J 2011;15:1389-99.

19. Singh K, Bloom S, Brodish P. Gender equality as a means to improve maternal and child health in Africa. Health Care Women Int 2015;36:57-69.

20. Pandey S, nim Lee H. Determinants of child immunization in Nepal: The role of women's empowerment. Health Educ J 2012;71:642-53.

21. Singh L, Rai RK, Singh PK. Assessing the utilization of maternal and child health care among married adolescent women: evidence from India. J Biosoc Sci 2012;44:1-26.

22. Herceg A, Daley C, Schubert $P$, et al. A population-based survey of immunisation coverage in two-year-old children. Aust J Public Health 1995;19:465-70.

23. Cotter JJ, Bramble J, Bovbjerg VE, et al. Timeliness of immunizations of children in a Medicaid primary care case management managed care program. J Natl Med Assoc 2002;94:833.

24. Antai D. Faith and child survival: the role of religion in childhood immunization in Nigeria. J Biosoc Sci 2009;41:57-76.

25. Singh PK. Trends in child immunization across geographical regions in India: focus on urban-rural and gender differentials. PLOS One 2013;8:e73102

26. Miyahara R, Jasseh M, Gomez $\mathrm{P}$, et al. Barriers to timely administration of birth dose vaccines in The Gambia, West Africa. Vaccine 2016;34:3335-41.

27. McKee C, Bohannon K. Exploring the reasons behind parental refusal of vaccines. J Pediatr Pharmacol Ther 2016;21:104-9.

28. Warraich HJ. Religious opposition to polio vaccination. Emerging Infect Dis 2009;15:978

29. Malik AS. In Pakistan, religious leaders help change misconceptions about the polio vaccine. 19 April 2012 ed. UNICEF, 2012.

30. Scientific American (2013) How the CIA's fake vaccination campaign endangers us all. http://www.scientificamerican.com/article.cfm? id=how-cia-fakevaccination-campaign-endangers-us-all (accessed 18 May 2015)

31. Khan MU, Ahmad A, Aqeel T, et al. Knowledge, attitudes and perceptions towards polio immunization among residents of two highly affected regions of Pakistan. BMC Public Health 2015;15:1.

32. Knowledge, attitudes and practices (kaps) polls in pakistan and nigeria (Tech. Rep.). (2014). Harvard School of Public Health, Harvard Opinion Research Program, and UNICEF. 